\title{
The Occurrence Mechanism of Air Traffic Control Hazards and Its Control Method
}

\author{
Xinyu Wang, Haolin Cui, Jie Yang \\ Department of Air Force Engineering University Air Traffic Control and Navigation College, Xi'an, \\ Shaanxi Province, China ,710051
}

32156743@163.com

Keywords: Occurrences; Airspace; Occur Mechanism

\begin{abstract}
With the rapid development of China's civil aviation industry and the increasing amount of air traffic flow, as one of the main security and civil aviation system, civil aviation system is facing new challenges. This paper discusses the impact of the system: human, mechanical, environmental and other factors that affect the air traffic control system security, analyze the three main components of air traffic control areas: man, machine and environment (airspace control room environment and microenvironment) for air traffic control system affect security; Based on accident causation theory, this paper analyzes the mechanism of ATC unsafe events.
\end{abstract}

\section{Introduction}

One of the main tasks of air traffic control work is to prevent midair collision of aircraft and aircraft to prevent the aircraft collided with the ground obstacles, guarantee smooth air traffic, where security is central to the work of air traffic controllers, is the primary criteria for evaluating the quality control efforts In the air traffic control of this complex man - machine - environment system, with the development of science and technology, and constantly improve the air traffic control automation technology, air traffic control operation has been greatly improved, but because the dominant in the air traffic control system. the role of the people - controllers, while the humanoid in physical, psychological, social and spiritual aspects, there is a greater degree of plasticity and difficult to control so-called human factor of substance is the people's initiative arising from production activities. the impact of internal relations in the modern aviation technology leapfrog development, aviation equipment and more advanced today, the human factor as the most important factor affecting aviation safety in world aviation history, aviation community to improve aviation security, promote global aviation safety level has gone through two stages: First, the early aircraft backward, people focus on flight safety improvements in technology to improve the second since the 1950's, in aviation technology has made considerable progress on the basis of people by accident. a lot of analysis and research to improve aviation after recognizing the technical level, regulatory lag has become an important factor affecting flight safety. This is the people began to develop regulatory and standardize aviation operations means, mechanism through a combination of regulatory and technological progress, resulting in a huge economic benefits. Up to now the Air Transport flight accident rate has been much lower than recognized as the most secure means of transport) train level, the aviation industry is no longer considered to be risk-takers in the industry, to become the world recognized as the most efficient, most convenient and safest modern means of transportation. From the 1950 s to the beginning of the seventies, the world's commercial fleet accident rate declined significantly, the accident rate decreased gradually weakened.

\section{The Features of the Air Traffic Control System}

Time service object ATC system is in a state of high-speed movement of aircraft, once the equipment malfunction or human operational errors occur, for correct and prevent accidents is very short, or even zero, the choice of the emergency mode is also extremely limited. Plus aircraft, high cost of airport security facilities and other hardware devices, the value carried by the aircraft of passengers, cargo is immeasurable, the accident only caused huge property damage, casualties and 
environmental damage, and more importantly, its transport air transport Object) passenger and cargo no ownership and control over, but only to provide the necessary transportation services, accident losses involve extensive social factors, greatly damaged the image of civil aviation and even the government's prestige, it is difficult to estimate the severity of the social impact.

Run air traffic control system involves military aviation personnel and facilities, civil aviation, airlines, airports, air traffic control, meteorology, intelligence, communications and navigation and other sectors, because international flights may also relate to the relevant departments in several countries, and these coordination consistent operation must rely on scientific management more complex in our country, airspace, something uneven development: a variety of control communications, navigation and surveillance facilities vary widely, radar control, radar monitoring program under control, program control, etc. coexist.

From the viewpoint of system theory, the ATC system safety-related factors can be divided into four categories: people, machines, the environment and the management of this class has the following advantages: 1) it is the most basic elements that make up the production system from starting, from the most fundamental cause of the accident to proceed with a universal significance. 2) fully reflects the security is - term full, the entire element, the whole process of the activities of the people because the system is working as the main means of man, machine refers to human the control - collectively cut objects (including fixed and mobile devices), the environment is a person, machine coexistence of specific operating conditions (including internal and external environment). 3) To consider the human, machine, security rings impact, especially taking into account the interaction between the three, including people - people, people - machine, machine - machine, machine - ring, people - ring and man - machine - rings, etc. 4) To manage as a control, coordination means mutual relations coordinator, machines, loops, and through feedback system status information back to the management system to improve safety management, and ultimately get a more secure system.

\section{Analysis of Factors Affecting the Safety of Air Traffic Control}

The composition of the air traffic control system mainly consists of three parts, namely people (ATC), the machine (control equipment) and environment (external environment and micro-environment), a correct understanding of the impact these three parts of the air traffic safety, to improve the air security pipe system has a crucial role.

The Factors of Controllers. Firm and clear political direction, strong professional ethics and strict work style is an important ideological guarantee for the safety of air traffic control to protect civil aviation is no small matter, air traffic control work more is no small matter, everything is directly related to flight safety, if thought slight paralysis, work a little careless, no political responsibility, at any time may lead to a major accident, causing incalculable damage to the country and people's lives and property.

Physical qualities: simply include: physical and mood swings controllers should have a healthy body, the body is the capital of revolution, only with a healthy body in order to better control the work of one of the features in the controller is 24-hour working system, prolonged work in a tense state, the brain and the body and mind easily tired, like car drivers like to drive when tired is prone to accidents. control efforts not to fatigue posts, ATC posts ago to ensure their own health, full of energy, especially at night, a relatively small amount of flight activity, flight time interval is very long, it is easy to control who appears sleepiness, inattention, trance situation. Therefore, health the body is provided in the control work.

Psychological qualities belong to non-intelligence factors, focus on training and improve the psychological quality for air traffic control safety is important. With the high-tech equipment in the field of air traffic control and air traffic control technology is widely used increasingly complicated, in addition to having a higher political responsibility and skilled business skills as a safeguard, the psychological quality is also an essential part of the air traffic controllers have awareness of psychological quality exercise in peacetime work, improve the overall quality of the controller will play a positive role in promoting Mastering empty self-psychological adjustment methods to 
maintain psychological balance, will enhance their sense of responsibility and to update their knowledge play a catalytic role.

The contents of the controller's control skills included more extensive, is mainly a controller integrated control capability. Important include reaction capability, distribution and control of air-ground coordination call capability, the ability to predict and deal with conflict, attention, etc.

The Factors of Equipment. With continuous innovation and rapid development of the aviation industry in the field of science and technology, air traffic control automation degree also with increasing flight traffic and continues to increase. The first stage is the first generation of air traffic control automation system is 7 years, from the late French Thomson introduced, were installed in the Beijing Capital International Airport and Shanghai Hongqiao Airport. Since the main function of this system is the generation of radar target data display, called the radar terminal displays. China Air Traffic Management Automation System in the strict sense is From the use of the second generation before the official start of the second-generation air traffic control automation system 21-1990s, China's civil aviation began to invest heavily in improving its air traffic control infrastructure, it has introduced a Raytheon (RAYTHEON), Delhi peak Knicks (Telephones) and Lockheed Martin Corp.'s radar display terminal processing system, were installed in Beijing, Guangzhou and Shanghai. The name of the automation system is introduced at the 1994 Beijing Raytheon terminal processing and display system, the first official use of third-generation air traffic control on behalf of the third-generation air traffic control automation system automation system is China's civil aviation is under construction in Beijing, Shanghai and Guangzhou, three regional control centers of air traffic control automation system.

\section{The Control Method Mistakes}

With the rapid development of China's civil aviation industry and the increasing flight traffic nationwide, the impact of human errors ATC system security has become more important, but it has also become one of the main factors endangering the safety of civil aviation in the aviation industry is increasingly developed today, how to predict, human error evaluation and control controller has important significance to improve the safety of air traffic control systems.

Improve the Status of ATC. Cultivate a good air traffic control officers generally take several years not only it requires air traffic controllers must possess technical skill, but requires some experience and experience technology and experience of air traffic control personnel need to undergo training. - Posts - retraining this cyclical process to accumulate and improve Thus, air traffic control personnel on a regular basis to learn, regular training, regular simulation training, combined with practical, well organized regular air traffic control and accident analysis commenting experience. Exchange activities are to improve the air traffic control staff skills and experience to increase the effective method.

Air traffic control service is achieved through the controller, to improve their own quality control staff and operational quality is an important way to avoid the human factor. Now China's civil aviation and gradually formed a three-tier training system to develop training, qualification training and improve training.

Improve Equipment Condition. Eliminating empty tube increased automation of the negative effects of flight safety, air traffic control must be functional automation system itself to be perfect should first ensure controllers in the use of air traffic control automation system control efforts, to maintain adequate working to stimulate the amount of aviation analogy concept of management scholars in incentives, to bring increased automation and tedious work to make a lot of research; they pointed out that with increased automation will reduce the traditional air traffic control work pressure brought stimulation, which is a source of low stimulation produces air traffic control work sense of oppression, of course, stimulate excessive regulation will bring instability to work. So we can see that reasonable adjustments ATC automated system for the understanding of the mind, so as to ensure good mental state controllers and some work emergency, it is an effective way to solve the problem of air traffic safety under the new form. 
Improving the Regulatory Environment. Currently, the national unified control, respectively directing air traffic control system, under the leadership of the Central Military Commission of the State Council, Air Traffic Control, Air Force, organized and implemented by the country's air traffic control, military aircraft, military aircraft from the implementation of command, civilian aircraft and foreign airlines aircraft by the Civil Aviation implement command. this system exists airspace bull command, coordination of complex issues such as military and civil aviation.

\section{Conclusion}

With the rapid development of China's civil aviation, air traffic control problems which are due to unsafe event have become a proposition aviation industry and those require constant research. We believe some analysis and attempts made by this article and our air traffic control system are good to improve security and can play a certain guidance meaning because of the air traffic control system is an open system for the community, but also be influenced by political, cultural and social factors such as age concept of finite own academic level. From a professional point of ATC this analyzed the system security, I feel pretty there are many deficiencies in the place worthy of further study. Since the broader aspects of running the air traffic control system is involved in the analysis of this paper does not quantify some factors, such as the environmental impact of the airspace. At the same time ATC safety proposed many methods of prediction and analysis which need to be verified and be improved in the actual control efforts.

\section{References}

[1] Dhillon B.S. On Human Reliability. Microelectronics and Reliability, 198(2):371-373.

[2] Beehtel, W. and Richardson, R.C. Discovering Complexity. .Princeton, NJ: Princeton University Press. 1993.

[3] Hollande Re. Cognitive Reliability and Error Analysis Method. Oxford(UK): Elsevier Science Ltd.,1998.

[4] J.R. Williams. The Art of Instrument Flying Handbook. U.s. Department of Transportation, 1989. 